\title{
UNDERSTANDING THE EDUCATIONAL RATIONALE BEHIND LEARNING IN VIRTUAL REALITY: A HISTORICAL DEVELOPMENT VIGNETTE
}

\author{
Lana Frančeska Dreimane \\ University of Latvia, Latvia
}

\begin{abstract}
Over the centuries fast developing technology has always had the power to transform learning and education in previously unimaginable ways, but even with an abundance of options, meeting the needs of learners has become something of a competition to provide meaningful and effective learning modes and designs. Currently learning is seen as an engaging process which provides experiences and allows learners to develop skills and competences of different cognitive, emotional and psycho-motor complexity. Indeed, analysing and understanding the diverse needs of learners as well as designing the most effective stimuli for desired learning outcomes - being that topical or contextual knowledge - has become pivotal for educators, instructional designers, researchers and learning technology engineers. Thus, in order to design VR learning experiences, as well as to effectively learn using VR technology, it is instrumental to fully understand the educational rationale behind learning in VR and the affordances of VR space as a learning vehicle. This article presents a brief historical development vignette of the tectonic shifts in learning theories with the aim of providing a comprehensive view of the synergy between the theories that are most prominent in understanding the rationale behind learning in VR, and through that to offer a roadmap for further research. This study is based on an extensive literature analysis of learning theories related to learning in VR, including, Constructivism, Constructionism, Technology enhanced learning, learning taxonomies for classification of learning objectives and development stages and instructional models.
\end{abstract}

Keywords: learning theories, virtual reality, cognitive pedagogy, instructional design, education.

\section{Introduction}

For centuries education has been entrusted with the responsibility of enabling individuals to access knowledge and practical learning experiences in order to become active and competitive members of society and through that to ensure further sustainability of those societies. Questions as of how to better acquire, transfer, collect and structure knowledge, skills and 
competences have been part of society much earlier than the first academic attempts to understand their conceptualisation or definition. Through the process of creating multi-layered synergies and continuous disruption of the status quo - increasingly fast-developing technology has had the power to transform learning and education in previously unimaginable ways but, even with an abundance of options, meeting the needs of learners has become something of a competition to provide meaningful and effective learning modes and designs. Currently, learning is thought of as an engaging process which provides learning experiences and allows learners to develop skills and competences of different cognitive, emotional and psycho-motor complexity. Indeed, analysing and understanding the diverse needs of learners as well as designing the most effective stimuli for desired learning outcomes - being that topical or contextual knowledge - has become ever so pivotal for educators, instructional designers, researchers and learning technology engineers. Thus, in order to design VR learning experiences as well as to effectively learn using VR technology it is instrumental to fully understand the educational rationale behind learning in VR and the affordances of VR space as a learning vehicle.

Since 1956, Bloom's Taxonomy of Educational Objectives: The Classification of Educational Goals (Bloom et al., 1956) has been the standard for the systematisation and classification of educational objectives. Later, a former student of Bloom's -Anderson together with Krathwohl published a revised version of Bloom's Taxonomy in 2001, proposing the use of verbs over nouns to define the learning outcomes as competences or acquired skills and abilities. It must be noted that Anderson and Krathwohl considered creativity over evaluation within the cognitive domain (Anderson et al., 2001). Various taxonomies were developed by Instructional Design practitioners and researchers, such as Gagne's taxonomy which defined five levels of learning: verbal information, intellectual skills, cognitive strategies, motor skills and attitudes, and nine events of instruction which corresponded to learning processes (Gagne, 1985). Gagne's taxonomy classifies the learning process in terms of the degree of complexity of the mental processes involved. In 2007, Churches further developed the taxonomy proposed by Bloom, and Anderson and Krathwohl and published a Digital Taxonomy, which complements existing taxonomies of learning outcomes with six levels of digital skills (Churches, 2007).

Since the mid-1950s and all through the 1960s there was an ongoing, yet pivotal shift in education psychology from teaching and towards learning. Learning has always been, and will continue to be, a way for society or an individual to adapt to socio-economic changes as well as to foster them, thus creating a cyclical and ever-evolving process. An increased interest in learning also further steered academic discourse towards 
the potential of learning environments - both physical and social. Since the 1980s technology enhanced learning (TEL), often used synonymously with technology enabled learning (TEL) or technology enhanced education (TEE), have all gained increasing focus in the field of educational research. TEL was gaining its popularity in adult training as well as school classrooms, thus constantly pushing researchers and practitioners to look for more effective ways to apply existing learning models as well as to understand where TEL should be positioned.

Since the early 2000s, one of the most notable shifts in education has been the increasing use of the 'flipped classroom' approach. This method of blended learning focuses on delivering the content outside the classroom, often characterised as self-paced online lectures, thus allowing the classroom environment to become the primary platform for collaborative learning and further elucidation.

The use of a desktop computer was further revolutionised by the rapid development of user-friendly technological advancement, thus further extending learning possibilities to online platforms, smartphones and tablets. These developments served as further stimuli for the advancement of digital learning content and its application and interaction in order to achieve learning objectives. There has been much discussion around the question of whether e-learning can and should completely replace traditional learning models. Thus, currently the concept of blended learning is at the forefront. "Blended learning designates the range of possibilities presented by combining Internet and digital media with established classroom forms that require the physical co-presence of teacher and students" (Friesen, 2012, p. 1.). These technologies have transformed learning and have changed its position from being a support tool (mainly for visual, audio and video materials), to it asserting itself in the central role as a method of content delivery. In addition, this evolution has affected content creation itself, as there has been an increasing need for interactive content which would aid memory and attention retention (especially in younger learners), learnerfriendly layouts and structures as well as formats (e.g. video lectures). This need to interact in pair with the constant battle against dehumanisation of the learning process in turn has directed the attention of instructional designers to the immense possibilities of computer-generated simulations, which have been used for complex learning skills in aviation, army, navy and engineering since the 1960s. These computer-generated simulations were an attempt to realise a presumption that a learner should experience a stronger response (including memory and attention retention) to an experience, rather than to an abstract theoretical discussion of concepts, because, with simulation, (more precisely emulations) it is possible to fool the brain into believing it actually has had the real experience of 
performing a task or having had a certain remote or new experience. Thus, the name of the latest technology, which is the focus of this study, comes directly from the combination of two main attributing terms - 'virtual' and 'reality'. As defined by the Virtual Reality Society: "the definition of virtual reality comes, naturally, from the definitions for both 'virtual' and 'reality'. The definition of 'virtual' is near and reality is what we experience as human beings. Respectively, the term 'virtual reality' basically means 'near-reality'. This could, of course, mean anything but it usually refers to a specific type of reality emulation" (2017).

Virtual Reality has fascinated people since the 1950s (e.g. Heling and Sutherland) and since then it has increased its presence in our lives, not only through entertainment but also in the way it has affected and transformed medical procedures and services, first-response and the military, engineering, architecture, businesses, sports, arts, and technologies.

There has been a lot of excitement about the potential of VR technologies, and it must be noted that various 'tech-gurus' grew impatient during the continuous evolution of VR technologies and persistent attempts to make it accessible to the masses. One of the leading industries to be dramatically transformed by VR is education (Kapp, 2017 and CB Insights, 2018) and especially over the past decade, it is evident that VR indeed has transformed education in both senses: traditional classroom education and technology enhanced learning. Nevertheless, recent educational research does agree that there is still immense potential for further applications of VR for learning and the solutions it can offer (see Salzman, 1999; Kapp, O'Driscoll, 2010).

VR is already showing its benefit to the flipped classroom model. For instance, Google Expeditions - a software that enables students to virtually travel to exotic locations, adding context to history and geography lessons. Companies such as Immersive VR Education are using dynamic storytelling to better help students to engage with their subject material. VR has captured people's imagination and designers, developers, and enthusiasts have devoted countless hours to design, code and explore the possibilities of this exciting emergence of a long dream about the medium. Now there are various affordable and fast hardware systems such as Google Cardboard, Google Daydream View, the Oculus Go, Oculus Rift, Oculus Quest, Oculus Vive, Samsung Gear VR and HTC Vive enable consumers to experience high-quality VR first hand.

\section{Educational rationale behind learning in Virtual Reality}

Practitioners and researchers have been concerned with how learning takes place since the advent of civilisation. Just in the past two centuries a significant number of theories on how learning occurs have been 


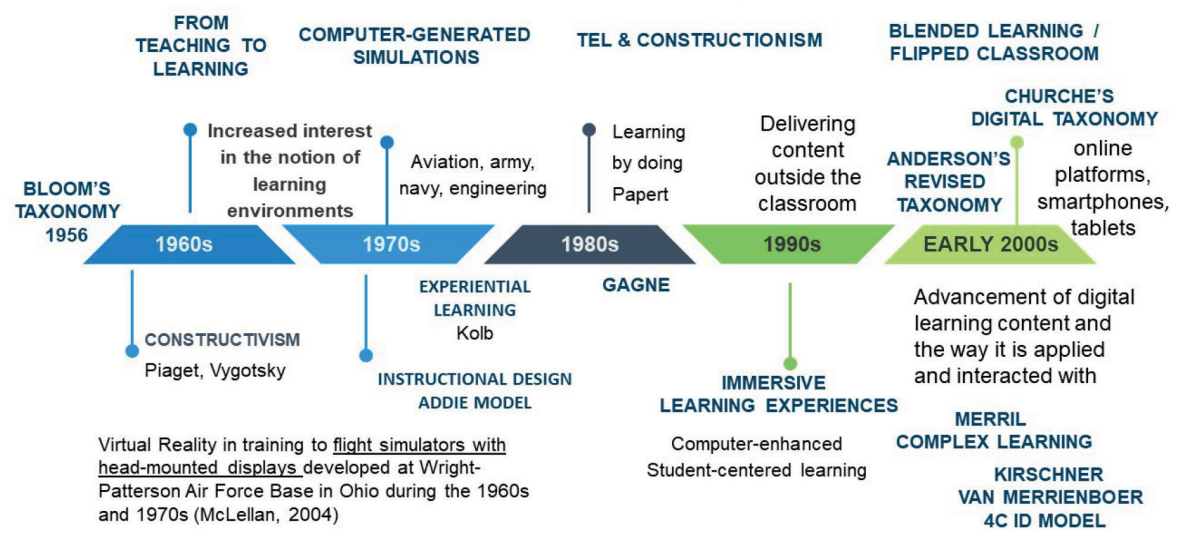

Figure 1. Development Vignette: Educational Psychology - Instructional Design - VR Technology, Author's concept

developed and introduced into educational practice internationally. In order to design VR learning experiences as well as to effectively learn using VR technology, first, it is necessary to look at the existing theories of learning, proposed models of the organisation of learning and the main shifts in academic discourse that have taken place since the 1950s.

To frame the discussion and in order to illustrate the tectonic shifts that have taken place in the fields of education, cognitive psychology, instructional design and VR technology, a historical development vignette is proposed by the author, see Figure 1.

\section{Constructivism}

Constructivist theory was developed in the mid-20 $0^{\text {th }}$ Century by several prominent educators, philosophers and academics. Two of the most prominent, which are often associated as synonyms of the theory itself, are Jean Piaget and Lev Vygotsky. Although their theories differ on a variety of detailed principles, there is an intertwining set of general principles which are viewed as the general constructivist theory (See Fig. 2). Both theorists believed that learners generate new knowledge and comprehension through building upon previously existing experiences, and those interactions between the experiences and the new information serve the point of 'knowledge construction' (Vygotsky, 1962, Piaget, 1976). Constructivism also argues that each individual's set of experiences and prior knowledge is different and unique, and thus, knowledge construction for each individual or potentially a homogenous group is different. Constructivism views learning as 'active' rather than 'passive'; thus one of the most significant contributions of this theory is the 'learner-centred' (sometimes also referred to as 'student-centred') approach rather than the content-centred 
approach to learning. In both Piaget's and Vygotsky's proposed approaches, educators have rather a support and guidance role rather than primary role of teaching new knowledge and skills and thus determining the course of a learning experience.

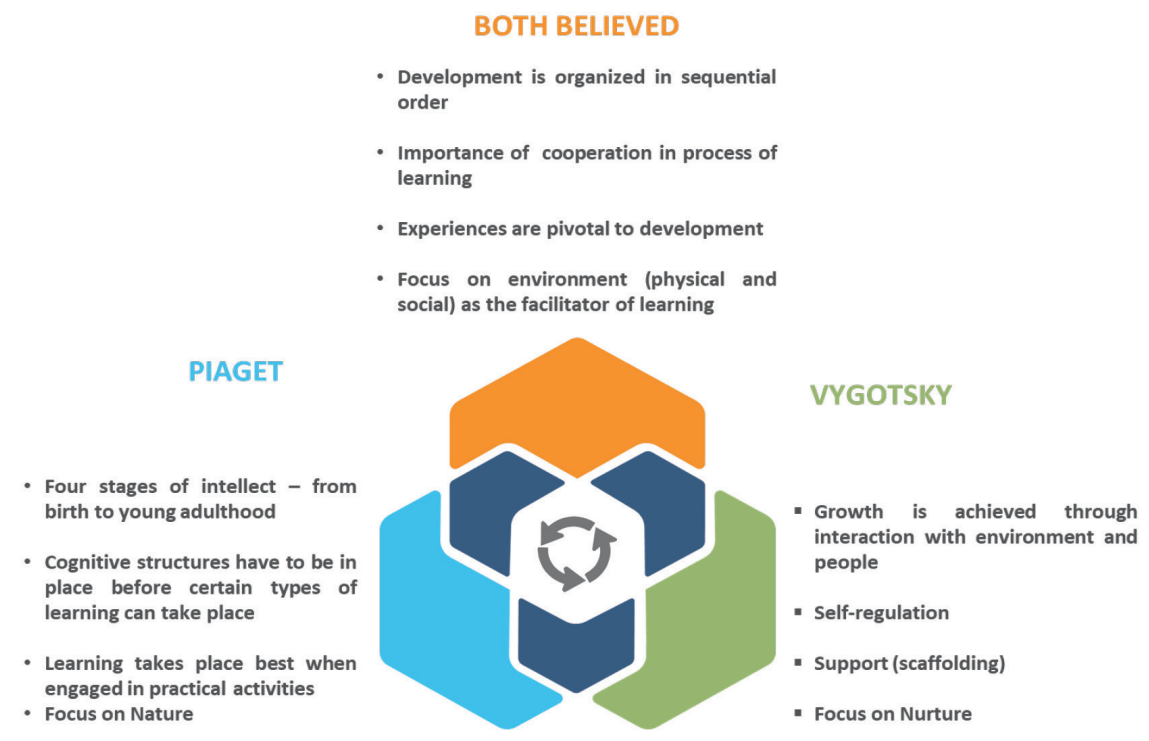

Figure 2. Overlap in Constructivist ideas - Piaget and Vygotsky, Author's concept

Social constructivism, a branch of constructivism, emphasises the importance of socio-cultural contexts of learning. Vygotsky believed that learning is dependent on social interaction and that 'social learning' actually leads to cognitive development (Vygotsky, 1962). Vygotsky emphasises the role of an educator as a support, guidance and scaffolding mechanism, as he believed that learners can perform tasks which otherwise they could not complete on their own, if given the necessary guidance or scaffolding, or alternatively through collaboration with their peers. This can be seen as a significant step towards experiential learning and instructional design in the future, as Vygotsky's model for teaching stresses the importance of learning opportunities and indeed, their design. He also believed that the type and quality of social interactions (culture, language, role-models to the student) determine the design and degree of development.

Constructivist learning theory is rooted in the premise that learning is an active process, where through various supportive mechanisms (environment both physical and social, information, guidance) learners develop connections with their prior experiences and knowledge and thus layer on or 'construct' the new knowledge, skills and attitudes. For the further development of 
learning in a virtual environment, this shift can be noted as one of the, pivotal moments when the academic discourse of the early constructivists, such as Wittrock and later Bloom, shifts its attention from 'teaching' to 'learning'. The course-changing impact of Piaget's theoretical ideas in educational psychology has in turn generated a great deal of research which has furthered our understanding of cognitive development and learning processes. Nonetheless, it also generated a notable amount of criticism; for instance, Vygotsky and Bruner (1966) in contrast to developmental stages, defined cognitive development as a continuum. Some later studies (Keating, 1979) critiqued Piaget, for neglecting the impact of socio-cultural environment on the cognitive development including the defined age ranges and development stages, and focusing only on the biological factors.

Nevertheless, constructivism is based on similar founding assumptions about learning and is one of the foundational theoretical inputs for learning in VR. There are two significant reasons why these theories serve as the foundation for this inquiry. First, constructivism places a great deal of importance on the creation of the suitable environment for knowledge construction rather than for its mere transfer from educator to learner, as the theory advocates knowledge construction, not knowledge reproduction. Secondly, constructivism stresses the importance of collaborative learning. These aspects are key to application of these pedagogical theories in order to study learning in VR, as the significance of the learning environment and collaborative experiences, draws direct parallels with the benefits of technology enhanced education including VR technology enhanced learning. Thus, this pedagogical framework will aid in designing and utilising VR learning experiences through learner engagement (environment) and prior experience based knowledge construction, thus facilitating the development of new knowledge and competences, such as critical and analytical thinking.

\section{Constructionism}

Constructionism theory, emphasises experiential discovery learning, where individuals or groups can learn and construct knowledge through practical, real-world tasks and experiences (Papert, 1991). During the 1980s Papert, who was also a mathematician, computer scientist, and one of the artificial intelligence (AI) pioneers and educators, developed the theory of Constructionism. Papert believed in learning by doing (Papert, 1980, 1993a, 1993b). He stressed that technology together with constructivist learning approach created opportunities for learners to construct new knowledge and new innovative ways of thinking. For Papert it was important to visualise the process of knowledge construction, thus allowing for more engaging experience. A strong parallel with constructivist theory is that Papert viewed learning as a pro-active process rather than 
passive as constructionism stresses enabling and learning versus teaching. Papert is often given credit for utilising technology in learning. Another strong similarity is a learner-centred approach to learning. Constructionism can be viewed as a branch of a constructivist learning approach, yet constructionism focuses on instruction rather than studies the process of learning. If there is a notable difference in the two theories discussed, it is that constructivism rather stresses the cognitive potential, whereas constructionism stresses the potential of the physical activity.

"Constructionism can mostly be found being used as an educational tool in science and math classrooms, though it is spreading to other subjects as well. Today, there is an increasing popularity for robotic technologies used in the classroom. Specifically, there has been a focus on "white-box" digital tools, which teach the user or builder about the structure of the technology itself, in contrast to "black-box" software or technology, which conceals the method of its creation and is closed to any modifications by the user or builder" (Alimisis \& Kynigos, 2009, p. 11).

In order to highlight the synergy with learning in VR, it must be noted that, the core statement of constructionism is that learning transpires through the process of creation both individually or collectively and that creation and co-creation can be achieved due to the affordances of the learning environment. Both in constructionism learning theory and learning in VR it is pivotal that the process of learning enables learners to have a close-up ownership over the learning process and its outcomes, while the educators and the learning environment provide the necessary guidance through scaffolding and feedback.

\section{Technology enhanced learning}

As highlighted in the Introduction, there is a variety of alternative terms used to discuss issues linked to technology and learning, however much of the discussion has been about how technology-enhanced learning (TEL) has been used, which is viewed as the application of ICT to achieve learning objectives.

According to Salomon: "Computer-based learning environments are not learning environments to which computers have been added ... Rather, these are relatively new environments in which computer-afforded activities have been fully integrated into other activities, affecting them and being affected by them" (1992, p. 252).

This principle directly transcends to development and organisation of TEL, as there are similar considerations as well as benefits and limitations imposed by the application of technologies. Various researchers have asked how technology enhances the value of learners' experiences. At the core of the TEL concept is the implication of a value 'upgrade' as a result of utilising 
technology for the betterment of the teaching and learning strategies. The description itself suggests that enhancement should be understood as a value judgement meaning improved quality or added value. Moreover, several academics (Kapp, O’Driscoll 2010; Kirkwood, Price, 2013) have raised questions, such as: what exactly can and should be, or in particular instances, is enhanced when technology utilised? How can an enhancement be evaluated and monitored?

These questions, as well as the potential benefits and risks concerned with TEL approach are similarly relevant to learning in VR, as without a strategic understanding of how the affordances of VR learning environment can and should be utilised, as well as how to evaluate, potentially measure and analyse this enhancement it can be really easy to fall into technology fascination effect. Furthermore, many of the TEL instructional design and teaching strategies can be applied to designing VR learning experiences and teaching using VR technology.

\section{Taxonomies and classifications of learning outcomes}

Various learning theories have been discussed in the previous sections and it is vital to emphasise the importance of the existing knowledge in this field, as it will be used to further develop a theory for systematisation of learning principles governing learning in VR.

There is a significant body of research available on the subject, yet for the purposes of this study, the following theories, ideas and classifications are explored and synthesised: Bloom, 1956; Gagne, 1985; Anderson and Krathwohl, 2001; Churches, 2007, Merrill, 2002, Kirschner and van Merriënboer, 2008. Some of the 'early' taxonomies include: Bloom's taxonomy (1956), the ADDIE model (1957), SOLO taxonomy by Biggs and Collis (Biggs \& Collis, 1982) and Gagne's taxonomy (1985).

In order to address the various classifications and taxonomies, the term Instructional Design (ID) will be introduced into the discussion, as it is often defined as the principal objective of such taxonomies and classifications, and also because it is often used in literature as an inter-changing alternative for learning - experiences, strategies, process mapping, management and monitoring.

Various taxonomies developed by ID practitioners and researchers (e.g. Gagne's Taxonomy (1985), and Bloom's Taxonomy (1956)) further reinforce the roots of Instructional design, both as a concept and a practice, reaching from cognitive and behavioural psychology, through constructivism, constructionism and TEL. "Instructional design is intended to be an iterative process of planning outcomes, selecting effective strategies for teaching and learning, choosing relevant technologies, identifying educational media and measuring performance" (Branch \& Kopcha, 2014, p. 77). 
The objective of ID, or instructional systems design (ISD), is "instructional experiences which make the acquisition of knowledge and skill more efficient, effective, and appealing" (Merrill, Drake, Lacy, Pratt, 1996, p. 5). The practice includes analysis of the learners' (or groups) current setting and prerequisites, later mapping out the needs of the learner, defining learning outcomes and the overall goals, followed by a designed learning experience, often described as an 'intervention'. Since the 1950s there have been approximately two hundreds instructional design models; however, conceptually, there are four conceptual models (Dick \& Carey, Kemp ISD, Guaranteed Learning / IDLS, First Principle of Instruction, Complex learning) yet most of them were derived from the ADDIE model, which is based on five stages of instruction: analysis, design, development, implementation, and evaluation.

One of the most renowned early models, developed by the Centre for Educational Technology at Florida State University for the U.S. military sector - ADDIE was developed in 1975.

Various taxonomies were developed by Instructional Design practitioners and researchers, including Gagne's Taxonomy which defined five levels of learning: verbal information, intellectual skills, cognitive strategies, motor skills and attitudes, and nine events of instruction which correspond to learning processes (Gagne, 1985). Gagne's Taxonomy classifies learning process in terms of the degree of complexity of the mental processes involved (see Figure 3). Subsequently, Churches further developed the taxonomy proposed by Bloom and Anderson and Krathwohl and published a digital taxonomy, which complemented existing taxonomies of learning outcomes with six levels of digital skills (Churches, 2007).

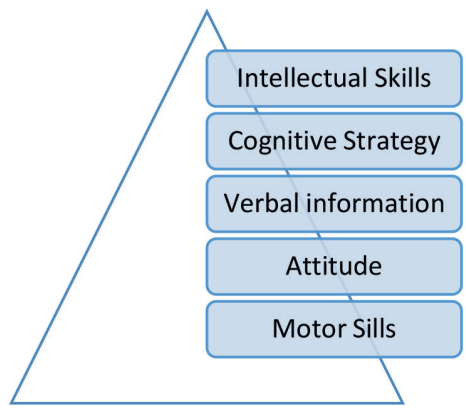

Figure 3. The Gagne's Taxonomy, Author's concept

Another significant direction for more contemporary learning models has been developed by Merrill, followed by Kirschner and van Merriënboer. The First Principles of Instruction (Merrill, 2002) is a model based on 
a synthesis of many earlier ID theories. The model focused on the aspects which were in common to the various ID theories, thus establishing the fundamental essence of ID through a set of principles. First Principles of Instruction can be applied in a Task or Problem-Centered cycle of instruction (see Figure 4). The model draws close parallels with other task-centred instructional theories, such as Kirschner and van Merriënboer (e.g. Four Component Instructional Design Model - 4C ID) as it uses a realworld problem or task as an instrument for instruction. Students observe demonstrations of examples of real-world problem solving, then are given opportunities to solve real-world problems themselves, while supported through feedback. Learning in context is pivotal in both the First Principles of Instruction and the 4CID model, as context becomes the core learning environment for deep learning.

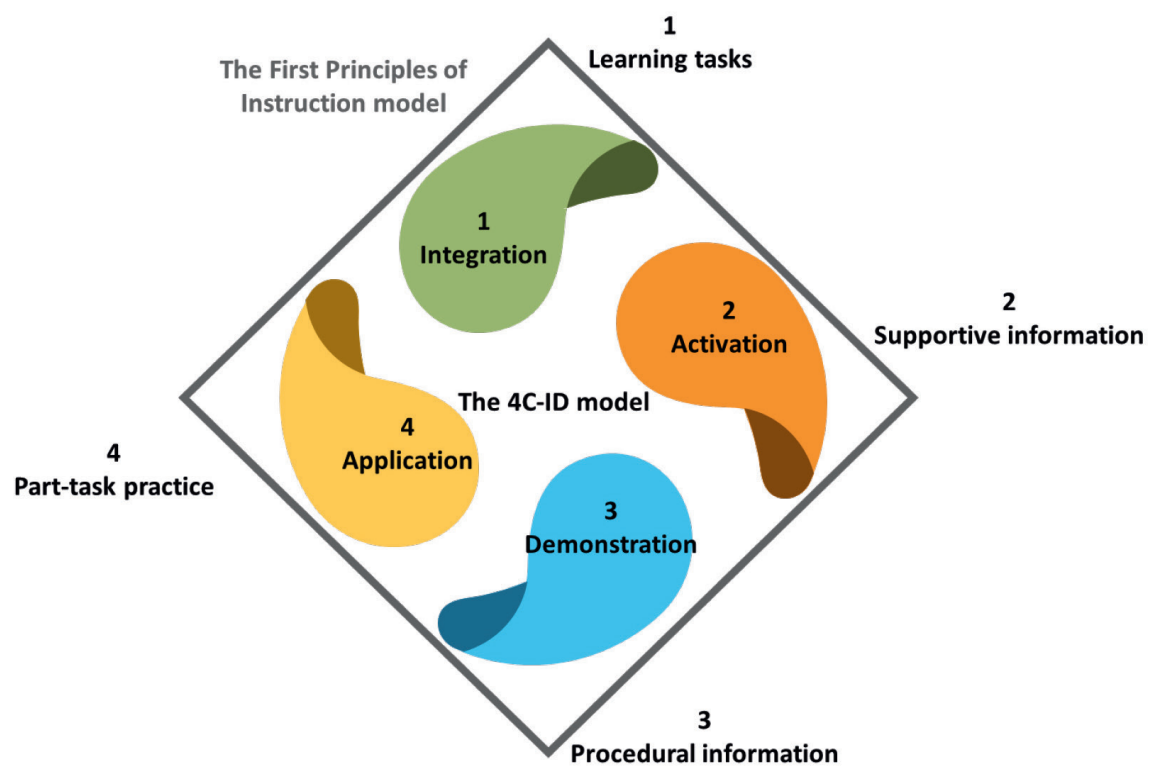

Figure 4. The First Principles of Instruction and the 4CID model, Author's concept

Works of Merrill (2002), Kirschner and van Merrienboer (2008) are of great significance to the understanding of how learning in VR should be organised and utilised, for a two main reasons:

1. Merrill attempts to synthesise most prominent ID approaches and models, thus providing a crucial impetus in presenting a comprehensive model for how learning takes place and to highlight the most effective ways to organise the learning process. 
2. Kirschner and van Merrienboer's 4C ID model presents a blueprint for complex learning, which is real-world based problem-solving. The model emphasises the real-world setting and supporting contextual information as well as varying and with progress diminishing guidance to a learner.

Thus, Merrill's model allows understanding of the general principles of the creation of learning experiences, while Kirschner's \& van Merrienboer's model, in fact, draws strong parallels with the principles often attributed to learning in VR, such as real-world simulation, contextual learning and varying guidance levels.

\section{Conclusion}

The theories explored in this study all have one central element in common - the potential of experience as an essential part of learning. Yet, it must be noted that there is no one single theory which would fit all, as there is no one form of learning that fits all objectives and all learners.

Constructivism and constructionism provide the best theoretic foundation for understanding of learning principles that govern learning in VR. Thirdly, Constructivism, Constructionism and TEL all emphasise the importance of a learner-centred approach to learning, where a learner takes an active role rather than a passive role. Next, the three learning theories, all emphasise the crucial importance of the learning environment thus accentuating the potential of VR technology application.

Meanwhile, the literature on VR learning argues that VR provides unique opportunities for learners to access learning experiences that otherwise would not be accessible as part of their formal classroom based education, and thus through VR to take part in that learning experience as it would have been a first-person experience.

For further research, a more detailed cross analysis of aspects of VR learning ecosystem that fit with the key facets of each of the major $20^{\text {th }}$ Century learning frameworks can be found in Dreimane, 2019 Virtual Reality Learning Experience Evaluation Tool for Instructional Designers and Educators In Daniela L. Eds. New Perspectives on Virtual and Augmented Reality: Finding New Ways to Teach in a Transformed Learning Environment. Taylor\&Francis. ISBN 9780367432119.

\section{References}

Alimisis, D., \& Kynigos, C. (2009). Constructionism and Robotics in Education. In D. Alimisis (Eds.), Teacher Education on Robotic-Enhanced Constructivist Pedagogical Methods (pp. 11-27). School of Pedagogical and Technological Education. 
Anderson, L. W.; Krathwohl, David R., eds. (2001). A taxonomy for learning, teaching, and assessing: A revision of Bloom's taxonomy of educational objectives. Allyn and Bacon. ISBN 978-0-8013-1903-7.

Bloom, B. S.; Engelhart, M. D.; Furst, E. J.; Hill, W. H.; Krathwohl, D. R. (1956). Taxonomy of educational objectives: The classification of educational goals. Handbook I: Cognitive domain. New York: David McKay Company.

Branch, R. M., \& Kopcha, T. J. (2014). Instructional design models. In Handbook of research on educational communications and technology (pp. 77-87). Springer New York.

Brown, J., Collins, A., \& Duguid, P. (1989). Situated Cognition and the Culture of Learning. Educational Researcher, 18(1), 32-42.

Bruner, J. S. (1966). Toward a theory of instruction. Cambridge, Mass.: Belkapp Press.

CB Insights. (2018, October 25). Research Briefs "Beyond Gaming: 19 Industries AR/VR Is Poised to Transform" Retrieved: https://www.cbinsights.com/research/ ar-vr-industries-disrupted-beyond-gaming/

Churches, A. (2007). Bloom's Digital Taxonomy. Retrieved from https://pdst.ie/sites/ default/files/BloomDigitalTaxonomy-AndrewChurches.pdf.

Friesen, N. (2012). Report: Defining Blended Learning. Retrieved: https://www. normfriesen.info/papers/Defining_Blended_Learning_NF.pdf.

Dreimane, L. F. (2019). Virtual Reality Learning Experience Evaluation Tool for Instructional Designers and Educators. In Daniela L. Eds. New Perspectives on Virtual and Augmented Reality: Finding New Ways to Teach in a Transformed Learning Environment. Taylor\&Francis. ISBN 9780367432119.

Gagne, R. (1985). The Conditions of Learning (4 ${ }^{\text {th }}$ Ed.). New York: Holt, Rinehart \& Winston.

Kapp, K. M., O'Driscoll, T. (2010). Learning in 3-D: Adding a New Dimension to Enterprise Learning and Collaboration. San Francisco, CA: Pfeiffer.

Kapp, K. M. (2017). 3 Instructional Design Strategies for Virtual Reality Learning. Published online - eLearning Industry: Instructional Design. (Retriewed: https:// elearningindustry.com/instructional-design-strategies-virtual-reality-learning).

Keating, D. (1979). Adolescent thinking. In J. Adelson (Eds.), Handbook of adolescent psychology. New York: Wiley.

Kirkwood, A., Price, L. (2013). Technology-enhanced learning and teaching in higher education: what is 'enhanced' and how do we know? A critical literature review, Learning, Media and Technology, 39:1, 6-36, DOI: 10.1080/17439884.2013.770404 Retrieved: https://www.tandfonline.com/doi/full/10.1080/17439884.2013.770404?scr oll $=$ top\&needAccess $=$ true.

Kirschner, P. A., \& Van Merriënboer, J. J. G. (2008). Ten steps to complex learning: A new approach to instruction and instructional design. In T. L. Good (Eds.), $21^{\text {st }}$ century education: A reference handbook. (pp. 244-253). Thousand Oaks, CA: Sage.

Mayer, R. E. and Wittrock, M. C. (1996). Problem-Solving Transfer. In Berliner, D. C. and Calfee, R. C., Eds., Handbook of Educational Psychology, Macmillan, New York.

McLellan, H. (2004). Virtual Realities. In Jonassen, D. H., \& Association for Educational Communications and Technology. Handbook of research on educational communications and technology. Mahwah, N.J: Lawrence Erlbaum. 
Merrill, M. D.; Drake, L.; Lacy, M. J.; Pratt, J. (1996). Reclaiming instructional design. Educational Technology. 36 (5): 5-7.

Merrill, D. (2002). First Principles of Instruction. Educational Technology Research and Development. Vol. 50, No. 3, 2002, ISSN 1042-1629. Retrieved: http://mdavidmerrill. com/Papers/firstprinciplesbymerrill.pdf.

Papert, S. (1980). Mindstorms: Children, computers and powerful ideas. New York: Basic Books.

Papert, S. (1993a). The Children's Machine: Rethinking School in the Age of the Computer. New York: Basic Books, Inc.

Papert, S. (1993b). Mindstorms ( $2^{\text {nd }}$ ed.). New York: Basic Books, Inc.

Papert, S., \& Harel, I. (1991). Situating constructionism. Constructionism, 36, p. 1-11.

Piaget, J., \& Cook, M. T. (1952). The origins of intelligence in children. New York, NY: International University Press.

Piaget J. (1976) Piaget's Theory. In: Inhelder B., Chipman H.H., Zwingmann C. (Eds.) Piaget and His School. Springer Study Edition. Springer, Berlin, Heidelberg.

Salomon, G. (1992). Effects with and of computers and the study of computer-based learning environments. Dans E. DeCorte, M. C. Linn, H. Mandl et L. Verschaffel (Eds.), Computer-based Learning Environments and Problem Solving (p. 249-263). Berlin: Springer-Verlag.

Salzman, M. C., Dede, C., Loftin, R. B., \& Chen, J. (1999). A model for understanding how virtual reality aids complex conceptual learning. Presence: Teleoperators and Virtual Environments, 8, 293-316.

Van Merriënboer, J. J., \& Kirschner, P. A. (2012). Ten steps to complex learning: A systematic approach to four-component instructional design. Routledge.

Virtual Reality Society. (2017). What is Virtual Reality?. (Retrieved May 2018: https:// www.vrs.org.uk/virtual-reality/what-is-virtual-reality.html ).

Vygotsky, L. S. (1962). Thought and Language. Cambridge, MA: MIT Press.

Vygotsky, L. S. (1978). Mind in Society. Cambridge, MA: Harvard University Press.

Winn, W. (1993). A conceptual basis for educational applications of virtual reality (Technical Report TR-93-9). Seattle, Washington: Human Interface Technology Laboratory, University of Washington. Retrieved July 2018: http://www.hitl. washington.edu/publications/r-93-9/. 